\title{
Adamo ed Eva. Le Jeu d'Adam: alle origini del teatro sacro, Edizione critica, traduzione e note a cura di Sonia Maura Barillari
}

\section{Walter Meliga}

\section{(2) OpenEdition}

\section{Journals}

\section{Edizione digitale}

URL: https://journals.openedition.org/studifrancesi/3011

DOI: 10.4000/studifrancesi.3011

ISSN: 2421-5856

\section{Editore}

Rosenberg \& Sellier

\section{Edizione cartacea}

Data di pubblicazione: 1 juillet 2013

Paginazione: 432

ISSN: 0039-2944

\section{Notizia bibliografica digitale}

Walter Meliga, «Adamo ed Eva. Le Jeu d'Adam: alle origini del teatro sacro, Edizione critica, traduzione e note a cura di Sonia Maura Barillari», Studi Francesi [Online], 170 (LVII | II) | 2013, online dal 30 novembre 2015, consultato il 02 février 2023. URL: http://journals.openedition.org/studifrancesi/3011 ; DOI: https://doi.org/10.4000/studifrancesi.3011

Questo documento è stato generato automaticamente il 2 février 2023.

\section{c) (†) $\odot$}

Creative Commons - Attribuzione - Non commerciale - Non opere derivate 4.0 Internazionale - CC BYNC-ND 4.0

https://creativecommons.org/licenses/by-nc-nd/4.0/ 


\title{
Adamo ed Eva. Le Jeu d'Adam: alle origini del teatro sacro, Edizione critica, traduzione e note a cura di Sonia Maura Barillari
}

\author{
Walter Meliga
}

\section{NOTIZIA}

Adamo ed Eva. Le Jeu d'Adam: alle origini del teatro sacro, Edizione critica, traduzione e note a cura di Sonia Maura BARILLARI, Roma, Carocci, 2010 («Biblioteca medievale», 126), pp. 318.

1 Questa nuova edizione critica del Jeu d'Adam si avvale di un'ampia e dettagliata introduzione che tocca tutti punti importanti di questo testo capitale per la storia del teatro e per l'intera letteratura medievale. La curatrice affronta l'articolazione tripartita del dramma e le sue fonti, la tecnica compositiva così come la struttura e il significato del testo, specialmente in relazione alla questione della sua unitarietà o meno; uguale attenzione è prestata ai rapporti fra il volgare del testo drammatico e il latino degli inserti liturgici e delle didascalie e pure alla componente più propriamente drammaturgica, che fa del Jeu una macchina teatrale piuttosto complessa, con messa in scena ed "effetti speciali". Sono poi ancora toccati i rapporti di parti o aspetti del Jeu con i programmi iconografici di alcuni monumenti medievali.

2 Dal punto di vista interpretativo manca un apprezzamento più ampio della posizione del testo nella storia dell'estetica letteraria medievale, ed europea in generale, nel solco del rilievo che Erich Auerbach dà al testo in uno dei capitoli di Mimesis. Una ripresa, eventualmente dialettica, dell'idea auerbachiana del Jeu come esempio di sublime cristiano non sarebbe stata di troppo, proprio in un'edizione come la presente che dimostra una spiccata - e peraltro quasi sempre riuscita - attenzione critica. 
3 L'introduzione si conclude con una sommaria descrizione della lingua e della versificazione, alcune precisazioni di ordine paleografico e interpuntivo a proposito del testo dell'unico manoscritto e con una ricca bibliografia.

4 Il testo critico è accompagnato da una traduzione italiana e da un dettagliato apparato critico che riporta gli interventi operati dai precedenti editori; seguono brevi note al testo e il glossario delle parti francesi del Jeu. In effetti le note al testo avrebbero potuto essere più ampie e argomentate, in particolare nei punti in cui l'introduzione non offre indicazioni in merito e nei casi in cui le soluzioni testuali adottate dagli editori nei confronti del testo tramandato sono state differenti. 